\title{
Drugs and the liver
}

\section{Drug metabolism in liver disease}

\author{
L. F. PRESCOTT, J. A. H. FORREST, K. K. ADJEPON-YAMOAH, AND \\ N. D. C. FINLAYSON \\ From the University Department of Therapeutics, The Royal Infirmary, Edinburgh
}

The liver is the most important site of drug metabolism and patients with liver disease might be expected to have a reduced capacity to metabolize drugs. The rates of elimination of extensively metabolized drugs such as the barbiturates, diazepam, tolbutamide, isoniazid, phenylbutazone, rifampicin, lignocaine, paracetamol, aminopyrine, antipyrine and pethidine have been measured in patients with liver disease (Nelson, 1964; Levi, Sherlock, and Walker, 1968; Held and von Olderhausen, 1971; Prescott, Wright, Roscoe, and Brown, 1971; Mawer, Miller, and Turnberg, 1972; Branch, Herbert, and Read, 1973; Klotz, Avant, Wilkinson, Hoyumpa, and Schenker, 1973; Prescott and Stevenson, 1973; Thomson, Melmon, Richardson, Cohn, Steinbrunn, Cudihee, and Rowland, 1973; Adjepon-Yamoah, Nimmo, and Prescott, 1974; Hepner and Vesell, 1974; Hvidberg, Andreasen, and Ranek, 1974; Klotz, McHorse, Wilkinson, and Schenker, 1974). The results of these studies are conflicting, however, and it seems that many patients with chronic liver disease can metabolize drugs at a normal rate. In keeping with these observations, Schoene, Fleischmann, Remmer, and Olderhausen (1972) found that cytochrome P-450-activity and the demethylation rates of aminopyrine and $p$-nitroanisole in liver biopsy specimens from patients with liver disease were not reduced unless the patient had severe hepatitis or cirrhosis. Cytochrome-c-reductase activity was not reduced at all even in the most seriously damaged livers. On the other hand, drugmetabolizing enzyme activity was reduced in liver biopsies from patients with primary and secondary hepatic tumours (Pelkonen, Karki, and Larmi, 1973).

Plasma cholinesterase is produced in the liver and the reduced activity of this enzyme in patients with liver disease is presumably due to impaired synthesis. Abnormally slow hydrolysis of drugs such as acetylsalicylic acid and procaine has been described in such patients (Reidenberg, James, and Dring, 1972). In contrast to the variable results observed in man, acute and chronic liver damage induced in experimental animals by agents such as carbon tetra- chloride results in predictable and significant depression of drug metabolism (Dingell and Heimberg, 1968; Vorne and Arvela, 1971).

\section{Theoretical Considerations}

A number of factors must be taken into account in assessing the effects of liver disease on drug metabolism. The plasma half-life of a drug is the most clinically useful index of drug-metabolizing capacity but it is not necessarily the most appropriate measurement. This is because the drug half-life $\left(t \frac{1}{2}\right)$ is determined by two independent variables, the apparent volume of distribution $\left(V_{D}\right)$ and the plasma clearance of drug: $t_{\frac{1}{2}}=\frac{0.693 \times V_{D}}{\text { clearance }}$. Both variables may be abnormal in liver disease. The volume of drug distribution may be increased in patients with ascites and oedema, and this would tend to increase the halflife. On the other hand, reduced binding of drugs to plasma proteins in patients with hypoalbuminaemia may result in an increased hepatic clearance and shortened half-life because more drug is unbound and available for metabolism. The plasma clearance of unbound drug is probably the best index of hepatic drug-metabolizing capacity.

Some other relevant factors are listed in table I, the most important being functional liver cell mass, enzyme activity, hepatic blood flow and previous drug therapy. The functional liver cell mass is obviously of importance. It may be increased or decreased in chronic liver disease but it is necessarily reduced in acute hepatic necrosis. Similarly, drugmetabolizing enzyme activity must be reduced in

\begin{tabular}{ll}
\hline Functional liver cell mass & Abnormal drug binding or \\
Drug-metabolizing enzyme & transport \\
activity & Retention of bile acids \\
Liver blood flow & Changes in volume of drug \\
Porto-systemic shunting & distribution \\
& Other drug therapy \\
\hline
\end{tabular}

Table I Factors influencing drug metabolism in patients with liver disease 
acute hepatic necrosis. Previous drug therapy should be taken into account since any impairment of drug metabolism due to disease may be more than offset by induction of microsomal enzymes(Leviet al,1968).

The effect of a reduction in hepatic blood flow on the plasma clearance of a drug depends largely on its normal hepatic extraction ratio (Gillette, 1971). If the hepatic extraction ratio is high, the liver removes most of the drug presented to it, and the clearance is limited by the hepatic blood flow. Thus the hepatic clearance of a drug such as lignocaine (extraction ratio $\mathbf{0 . 7}$ ) is very dependent on liver blood flow. Conversely, changes in hepatic blood flow would have very little effect on the clearance of antipyrine (extraction ratio 0.03 ) since only $3 \%$ of the drug delivered to the liver is metabolized and enzyme activity rather than blood flow is the limiting factor. Total liver blood flow may be increased in acute alcoholic and viral hepatitis and alcoholic cirrhosis (Cohn, Khatri, Groszmann, and Kotelanski, 1972; Lundbergh and Strandell, 1974) but effective flow may be reduced by oedema in acute liver damage and it is often greatly decreased in cirrhosis by portosystemic shunting (Groszmann, Kotelanski, Cohn, and Khatri, 1972). Because of the dependence of elimination of drugs with a high hepatic extraction ratio on liver blood flow, reduction in cardiac output may have a much greater effect on the plasma clearance than reduced drug-metabolizing enzyme activity resulting from liver disease.

Most studies of drug metabolism in patients with liver disease have been carried out by pharmacologists and little attention has been given to the underlying pathology. Because of the differential effects of reduced liver blood flow and decreased enzyme activity, it is theoretically possible for the elimination of one drug to be abnormal while another drug is handled virtually normally. Similarly, it is not surprising that the plasma half-life of antipyrine is normal in patients with obstructive jaundice (Elfström and Lindgren, 1974) since this drug is not excreted into bile. However the half-life of drugs which have an enterohepatic circulation or are extensively secreted into bile, eg, rifampicin, would probably be prolonged. It is clear that not only must the nature and severity of the liver disease be taken into account, but also haemodynamic factors and the pharmacokinetic characteristics of the drugs studied.

\section{Acute Liver Disease}

Relatively few studies seem to have been carried out in patients with acute liver disease. Levi et al (1968) found that the plasma half-life of isoniazid was prolonged in some patients with acute hepatitis. The prolongation of the isoniazid half-life in the whole series, however, was considered to be quantitatively less important than the basic genetic differences in acetylator phenotype. In another study, the half-life of tolbutamide was actually shorter than normal in patients with acute hepatitis, possibly because the drug is displaced from plasma proteins by bilirubin (Held and von Oldershausen, 1971).

We have studied drug metabolism in patients with acute hepatic necrosis following paracetamol overdosage. The rate of metabolism of paracetamol itself is directly related to the severity of the liver damage, and is a valuable guide to the prognosis (Prescott $e t$ $a l, 1971)$. In two patients who eventually died in hepatic failure, the plasma paracetamol half-life was increased from a normal value of $2.0 \pm 0.4$ (SD) hours to about 25 and 60 hours (Prescott and Wright, 1973). The plasma antipyrine half-life is also significantly prolonged in patients recovering from paracetamol-induced hepatic necrosis (Forrest, Roscoe, Prescott, and Stevenson, 1974). In 17 such patients the antipyrine half-life was $20.6 \pm 7 \cdot 3$ (SD) hours compared with a normal value of $12.0 \pm 3.5$ (SD) hours (O'Malley, Crooks, Duke, and Stevenson, 1971). The antipyrine half-life was measured an average of $3 \cdot 2$ days after the paracetamol overdose, at which time the mean serum alanine aminotransferase (SGPT) activity was 891 i.u./l. There were sta-

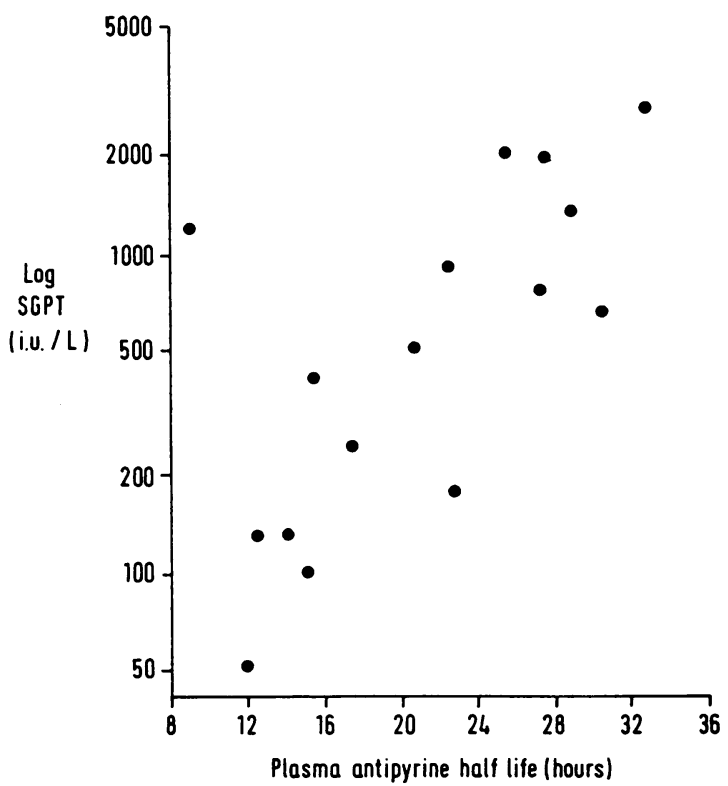

Fig 1 Correlation between plasma antipyrine half-life and SGPT in patients with acute hepatic necrosis following paracetamol overdosage (from Forrest et al, 1974, Brit. med. J., 4, 499-502). 
tistically significant correlations between the antipyrine half-life and the paracetamol half-life, SGPT, serum bilirubin and prothrombin time ratio (fig 1). The antipyrine half-life returned virtually to normal over a period of seven to 21 days. The metabolism of barbiturates and diphenylhydantoin is also impaired in patients with liver damage caused by paracetamol. Combined overdosage with paracetamol and barbiturates is particularly dangerous and coma may be prolonged (Prescott and Stevenson, 1973).

\section{Chronic Liver Disease}

As mentioned above, variable results have been obtained in previous studies of drug metabolism in patients with chronic liver disease. We have measured the plasma half-lives of antipyrine, paracetamol and lignocaine after single oral doses of approximately 18,20 and $6 \mathrm{mg} / \mathrm{kg}$ respectively in 19 such patients. Twelve patients received all three drugs and 16 received two. Antipyrine, paracetamol and lignocaine were chosen because they have different hepatic extraction ratios and are metabolized by different primary routes (table II). The diagnoses in these patients were alcoholic cirrhosis (11 patients), cryptogenic cirrhosis (2), primary biliary cirrhosis (3), sclerosing cholangitis (1) and active chronic hepatitis (2). The diagnosis was made on the basis of clinical and biochemical findings, and was confirmed in most cases by liver biopsy or postmortem examination. Only two patients had been taking drugs definitely known to cause enzyme induction. The results are summarized in table III.

In 16 of the 17 patients given lignocaine the plasma half-life was abnormally prolonged (more than the

\begin{tabular}{lll}
\hline Drug & $\begin{array}{l}\text { Major Route of } \\
\text { Metabolism }\end{array}$ & $\begin{array}{l}\text { Hepatic } \\
\text { Extraction } \\
\text { Ratio }\end{array}$ \\
\hline Antipyrine & Hydroxylation & 0.03 \\
Paracetamol & Conjugation & $0 \cdot 15$ \\
Lignocaine & N-dealkylation & 0.70 \\
\hline
\end{tabular}

Table II Characteristics of drugs studied

\begin{tabular}{|c|c|c|c|}
\hline & $\begin{array}{l}\text { Paracetamol } \\
t \frac{1}{2}(h r)\end{array}$ & $\begin{array}{l}\text { Antipyrine } \\
t \frac{1}{2}(h r)\end{array}$ & $\begin{array}{l}\text { Lignocaine } \\
t \frac{1}{2}(h r)\end{array}$ \\
\hline $\begin{array}{l}\text { Chronic liver disease } \\
\text { (mean and range) }\end{array}$ & $\left(1 \cdot 5^{3 \cdot 2}-7 \cdot 0\right)$ & $\left(4.9^{32 \cdot 9}-137\right)$ & $(1 \cdot 8-19 \cdot 0)$ \\
\hline $\begin{array}{l}\text { Healthy subjects } \\
\quad(\text { mean } \pm \text { SD) }\end{array}$ & $2 \cdot 0 \pm 0.4$ & $12 \cdot 0 \pm 3 \cdot 5$ & $1 \cdot 4 \pm 0 \cdot 26$ \\
\hline Mean percentage increase & 58 & 174 & 421 \\
\hline
\end{tabular}

Table III Plasma half-lives of antipyrine, paracetamol and lignocaine in patients with chronic liver disease

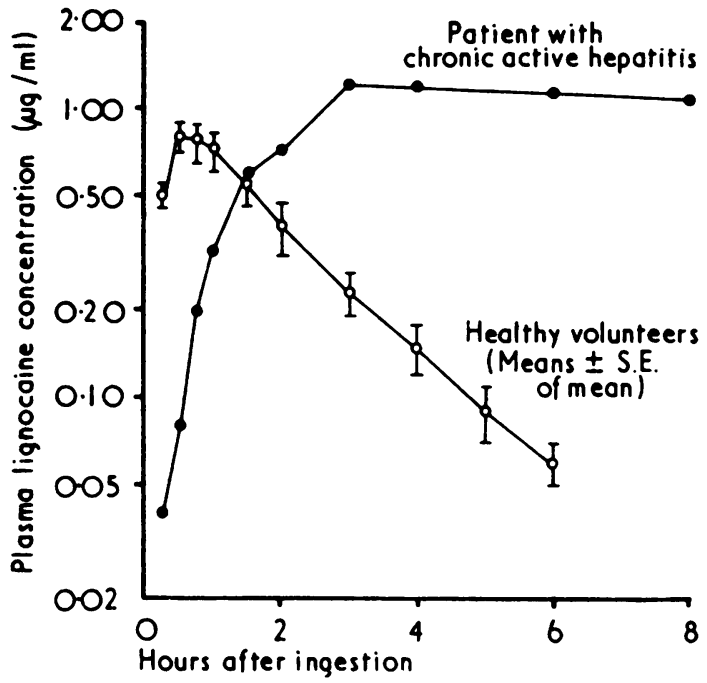

Fig 2 Plasma concentrations of lignocaine following an oral dose of $400 \mathrm{mg}$ in healthy volunteers and a patient with active chronic hepatitis (from Adjepon-Yamoah et al, 1974, Brit. med. J. 4, 387-388).

mean value +2 SD in healthy subjects). The mean lignocaine half-life in the patients $(7 \cdot 3$ hours) was more than five times the control value. The antipyrine and paracetamol half-life values were prolonged by the same criteria in only nine of 16 and seven of 14 patients respectively and the mean percentage increases were 174 and 58. Thus the lignocaine half-life seems to be the most sensitive index of impaired drug-metabolizing capacity in patients with chronic liver disease while the metabolism of paracetamol was least affected. Nevertheless, marked prolongation of the half-life of one drug was always associated with a correspondingly depressed metabolism of the other drugs, and there were highly significant correlations between the half-life values of the three drugs. The greater prolongation of the lignocaine half-life suggests that reduction in effective liver blood flow is more important than reduced drug-metabolizing enzyme activity as a cause of abnormally slow drug metabolism in patients with chronic liver disease. The elimination of paracetamol was not markedly impaired in most patients and similar observations were made by Fevery and de Groote (1969) although conjugation was somewhat reduced in their patients when the serum bilirubin exceeded $5 \mathrm{mg} / 100 \mathrm{ml}$. It is possible that a greater proportion of the paracetamol was conjugated at extrahepatic sites, such as the intestinal mucosa which is rich in glucuronyl transferase and aryl sulphatase. Alternatively, in chronic liver disease 
there might be selective impairment of different routes of drug metabolism since the major metabolic reactions involved in the removal of the three drugs are different (table II).

There were statistically significant correlations between the half-lives of all three drugs and serum albumin levels and vitamin K-corrected prothrombin time ratios, but not with SGPT and alkaline phosphatase activity and serum bilirubin. Abnormally slow drug metabolism was therefore related more to the severity than to the activity of disease. One patient with active chronic hepatitis had gross impairment of drug metabolism of a degree not previously described. The lignocaine and antipyrine half-life values were 19 and 137 hours respectively and both drugs were metabolized at only $7-8 \%$ of the normal rate. Such severe depression of drug metabolism represents a serious hazard to the patient since most drugs given in conventional dosage would cumulate rapidly and produce serious if not fatal toxicity (Adjepon-Yamoah et al, 1974). In this study, as in others (Mawer et al, 1972; Branch et al, 1973), impaired drug metabolism in patients with chronic liver disease was correlated with low serum albumin and increased prothrombin time but this is of little help in deciding drug dosage in an individual patient. In such circumstances drug metabolism studies should be carried out to minimize the risk of therapeutic disaster.

\section{References}

Adjepon-Yamoah, K. K., Nimmo, J., and Prescott, L. F. (1974). Gross impairment of hepatic drug metabolism in a patient with chronic liver disease. Brit. med. J., 4, 387-388.

Branch, R. A., Herbert, C. M., and Read, A. E. (1973). Determinants of serum antipyrine half-lives in patients with liver disease. Gut, 14, 569-573.

Cohn, J. N., Khatri, I. B., Groszmann, R. J., and Kotelanski, B. (1972). Hepatic blood flow in alcoholic liver disease measured by an indicator dilution technic. Amer. J. Med., 53, 704-714.

Dingell, J. V., and Heimberg, M. (1968). The effects of aliphatic halogenated hydrocarbons on hepatic drug metabolism. Biochem. Pharmacol., 17, 1269-1278.

Elfström, J., and Lindgren, S. (1974). Disappearance of phenazone from plasma in patients with obstructive jaundice. Europ. $J$. clin. Pharmacol., 7, 467-471.

Fevery, J., and de Groote, J. (1969). Conjugation of N-acetyl-paminophenol (NAPA) in adult liver patients. Acta hepatosplenol. (Stutt.), 16, 11-18.

Forrest, J. A. H., Roscoe, P., Prescott, L. F., and Stevenson, I. H. (1974). Abnormal drug metabolism after barbiturate and paracetamol overdose. Brit. med.J., 4, 499-502.
Gillette, J. R. (1971). Factors affecting drug metabolism. Ann. N.Y. Acad. Sci., 179, 43-66.

Groszmann, R., Kotelanski, B., Cohn, J. N., and Khatri, I. M. (1972). Quantitation of portasystemic shunting from the splenic and mesenteric beds in alcoholic liver disease. Amer. J. Med., 53, 715-722.

Held, H., and von Oldershausen, H. F. (1971). Drug metabolism in acute and chronic liver disease. (Abstr.) Digestion, 4, 151.

Hepner, G. W., and Vesell, E. S. (1974). Assessment of aminopyrine metabolism in man by breath analysis after oral administration of ${ }^{14} \mathrm{C}$-aminopyrine. New Engl. J. Med., 291, 1384-1388.

Hvidberg, E. F., Andreasen, P. B., and Ranek, L. (1974). Plasma halflife of phenylbutazone in patients with impaired hepatic function. Clin. Pharmacol. Ther., 15, 171-177.

Klotz, U., Avant, G. R., Wilkinson, G. R., Hoyumpa, A., and Schenker, S. (1973). Altered disposition and elimination of diazepam in patients with liver disease. (Abstr.) Gastroenterology, 65, 552 .

Klotz, U., McHorse, T. S., Wilkinson, G. R., and Schenker, S. (1974). The effect of cirrhosis on the disposition and elimination of meperidine in man. Clin. Pharmacol. Ther., 16, 667-675.

Levi, A. J., Sherlock, S., and Walker, D. (1968). Phenylbutazore and isoniazid metabolism in patients with liver disease in relation to previous drug therapy. Lancet, 1, 1275-1279.

Lundberg, P., and Strandell, T. (1974). Changes in hepatic circulation at rest, during and after exercise in young males with infectious hepatitis compared with controls. Acta med. scand., 196, 315-325.

Mawer, G. E., Miller, N. E., and Turnberg, L. A. (1972). Metabolism of amylobarbitone in patients with chronic liver disease. Brit. J. Pharmacol., 44, 549-560.

Nelson, E. (1964). Rate of metabolism of tolbutamide in test subjects with liver disease or with impaired renal function. Amer. J. med. Sci., 248, 657-659.

O'Malley, K., Crooks, J., Duke, E., and Stevenson, I. H. (1971). Effect of age and sex on human drug metabolism. Brit. med.J., 3, 607-609.

Pelkonen, O., Karki, N. T., and Larmi, T. K. I. (1973). Liver drug metabolism in tumor-bearing surgical patients. Chir. Gastroent. (Engl. ed.), 7, 436-443.

Prescott, L. F., and Stevenson, I. H. (1973). Liver disease and drug metabolism in man. In Pharmacology and the Future of Man: Proceedings of the 5th International Congress on Pharmacology, edited by G. H. Acheson. Vol. 3, pp. 182-190. Karger, Basle.

Prescott, L. F., and Wright, N. (1973). The effects of hepatic and renal damage on paracetamol metabolism and excretion following overdosage: a pharmacokinetic study. Brit.J. Pharmacol., 49, 602-613.

Prescott, L. F., Wright, N., Roscoe, P., and Brown, S. S. (1971). Plasma-paracetamol half-life and hepatic necrosis in patients with paracetamol overdosage. Lancet, 1, 519-522.

Reidenberg, M. M., James, M., and Dring, L. G. (1972). The rate of procaine hydrolysis in serum of normal subjects and diseased patients. Clin. Pharmacol. Ther., 13, 279-284.

Schoene, B., Fleischmann, R. A., Remmer, H., and Oldershausen, H. F. v. (1972). Determination of drug metabolizing enzymes in needle biopsies of human liver. Europ. J. clin. Pharmacol., 4, 65-73.

Thomson, P., Melmon, K. L., Richardson, J. A., Cohn, K., Steinbrunn, W., Cudihee, R., and Rowland, M. (1973). Lidocaine pharmacokinetics in advanced heart failure, liver disease and renal failure in humans. Ann. intern. Med., 78, 499-508.

Vorne, M., and Arvela, P. (1971). Effect of carbon tetrachloride induced progressive liver damage on drug metabolising enzymes and cytochrome P-450 in rat liver. Acta pharmacol. et toxicol. (Kbh.), 29, 417-427. 